\title{
Thermal Analysis and Experimental Validation of Parabolic Trough Collector for Solar Adsorption Refrigerator
}

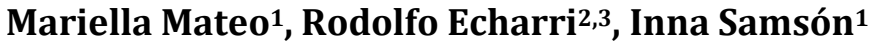 \\ ${ }^{1}$ Laboratorio de Energías Alternativas, Instituto Tecnológico de Santo Domingo, Santo Domingo, Dominican Republic \\ ${ }^{2}$ Instituto del Desarrollo Humano, Universidad Nacional de General Sarmiento, Buenos Aires, Argentina \\ ${ }^{3}$ Consejo Nacional de Investigaciones Científicas y Técnicas (CONICET), Buenos Aires, Argentina \\ Email: mariella.mateo@intec.edu.do,recharri@ungs.edu.ar, inna.samson@intec.edu.do
}

How to cite this paper: Mateo, M., Echarri, R. and Samsón, I. (2017) Thermal Analysis and Experimental Validation of Parabolic Trough Collector for Solar Adsorption Refrigerator. Energy and Power Engineering, 9, 687-702.

https://doi.org/10.4236/epe.2017.911044

Received: September 9, 2017

Accepted: October 15, 2017

Published: October 18, 2017

Copyright $\odot 2017$ by authors and Scientific Research Publishing Inc. This work is licensed under the Creative Commons Attribution International License (CC BY 4.0).

http://creativecommons.org/licenses/by/4.0/

\begin{abstract}
This work presents an algorithm able to simulate the heating of a solar collector throughout the day. The discussed collector is part of a solar adsorption refrigerator, and is used to regenerate the activated carbon contained inside a cylindrical recipient (absorber), which is located in the focal line of a parabolic trough concentrator. The developed algorithm takes into account all the transfer mechanisms when analyzing the heat transfers taking place between the collector's components and the environment, as well as the transfer mechanisms towards the absorber's interior. The temperature evolution for the collector's elements is obtained, and the model is validated by comparing the experimentally measured surface temperature of the absorber with the one determined by the algorithm. The experimental data were gathered from similar collectors in two different scenarios: Santo Domingo (Dominican Republic) and Buenos Aires (Argentina). The model is satisfactorily validated with experimental data.
\end{abstract}

\section{Keywords}

Mathematical Model, Heat Transfer, Parabolic Trough Collector, Solar Adsorption Refrigerator

\section{Introduction}

In the last decades, the research about adsorption refrigeration systems has risen since it can offer an alternative which is less harmful to the environment than the conventional refrigeration systems. Unlike the traditional vapor-compression 
systems, the adsorption refrigeration technology uses refrigerants with zero ozone depletion potential and zero global warming potential [1], and can operate without electrical or moving parts.

While the traditional refrigeration systems convert the consumed electricity into mechanical work in order to compress the working fluid, the functioning of an adsorption refrigeration system relies on the variable adsorbent capacity of a given refrigerant pair, which is caused by a temperature variation in the adsorbent bed, making that this kind of device can be easily powered by solar energy or waste heat.

When driven by solar energy, an adsorption refrigeration system can be built from affordable materials and its construction is relatively simple. Additional features such as silent operation and zero operative costs, make this kind of system worth implementing.

Many researchers are seeking to develop this type of refrigeration system, which could be used for everyday comfort as well as for higher priority purposes, such as vaccines and food storage, especially in those inhabited areas where the non-existent electricity distribution networks make difficult and expensive the utilization of the conventional refrigeration systems. Also regions with abundant solar energy resources could benefit from this king of technology. However, there are major drawbacks of the solar adsorption refrigeration (SAR) systems to be addressed: their low coefficient of performance compared with the traditional refrigeration systems, its discontinuous cold production, and the fact that the external operation conditions strongly affect the performance of the SAR cooling device; making difficult to predict its behavior.

A solar adsorption refrigeration system is based in the dynamics of the adsorbent-adsorptive refrigeration pair, which manifests as the capacity of the adsorbent material to adsorb and desorb the adsorptive fluid through the day.

A solar adsorption refrigeration device, as can be seen on Figure 1, is composed by the following parts: the absorber (where the refrigerant pair is located), a condenser, an evaporator, and a cold chamber.

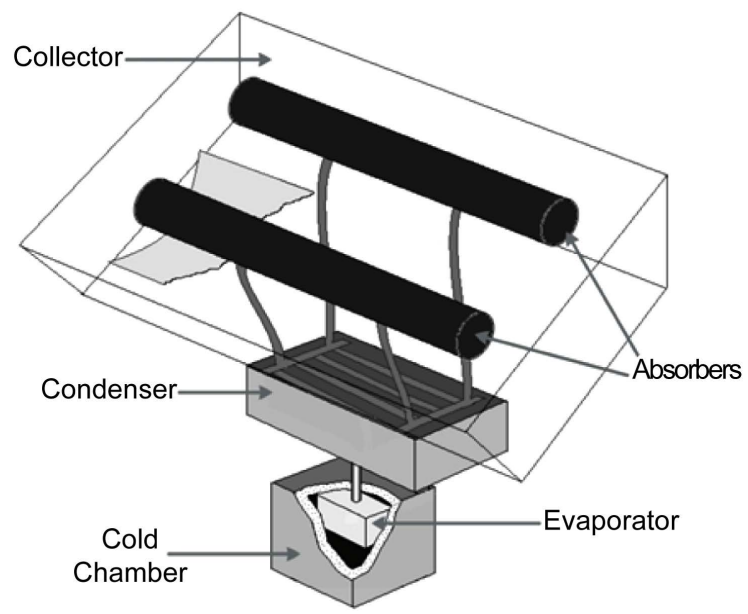

Figure 1. Scheme of solar cooling device. 
The refrigeration cycle of this device has been described by many researchers [2] [3] [4] [5] [6]. While exposed to solar radiation, the adsorbent absorbs the necessary energy to cause the desorption of the adsorbate. The adsorptive passes through the condenser, changing to the liquid phase in the process, releasing the heat of condensation to the environment and falling into the evaporator. When the solar radiation decreases, also the temperature of the adsorbent and the pressure of the system decrease, which eventually triggers the adsorption process which provokes the evaporation of the methanol previously desorbed. The necessary energy for the evaporation is extracted from the cold chamber, producing the cooling effect. Clearly, the amount of extracted heat is proportional to the quantity of adsorptive that circulates in the system along the whole day.

These devices are able to produce the cold intermittently, in a one-day cycle. For that reason is essential to produce a certain amount of ice during the night, in order to maintain a $0^{\circ} \mathrm{C}$ temperature in the cold chamber or perhaps allow a minimal temperature change during the day.

Some researchers have performed a thermodynamic design of a solar adsorption refrigerator [7], and designed algorithms to determine the amount of ice produced by these devices [8] [9]. However, these works are approximations based on the variation of the ratio adsorbate/adsorbent, analyzed with the corresponding conditions at two different stages of the day when the concentration of adsorbate in the absorbent are expected to be minimum and maximum, supposing equilibrium state between the two and fixed values of pressure and temperature. A more careful analysis would take into account that the concentration of adsorbate into adsorbent varies according to the temperature and pressure and, at the same time, these two varies as a function of time and depending on the concentration change.

In order to attain a more precise prediction of the behavior of a solar adsorption refrigerator, it is fundamental to understand the processes taking place in the absorber, where the refrigerant pair interact. Some research have been done concerning the dynamic of sorption; Luo and Tounder [10] developed a mathematical model in which the pressure on the system is supposed to remain constant, while Zao et al. [11] present a model in which is considered as a constant the temperature in the absorber's surface. Echarri et al. [12] developed a numerical model in which the temperature in the surface of the absorber and the pressure inside the vapor canal are considered variables.

In realistic conditions, the temperature on the surface of the absorber changes throughout the day, and this variation is influenced by multiple factors. Hence, in order to accurately determine the temperature evolution in the surface of the absorber, it is indispensable to develop a model that takes into account the absorber's net incoming energy and the energy consumed by the desorption process.

The objective of this study is to develop a physical model able to simulate the thermal behavior of a solar collector, which takes in account the climatic factors 
of the place where it is located, such as the solar radiation and the environmental temperature. The solar collector model could be coupled to models of devices that are powered by solar energy such as heat pumps, water heaters and, as intended in this work, adsorption refrigerators.

In order to obtain the usable heat entering the absorber tube, it is required to determine the incident solar radiation directed towards the absorber, and it is necessary to calculate the absorber's heat losses by performing a thermal analysis of the solar collecting system and its heat transfers with the absorber tube and with the environment.

The analyzed adsorption refrigeration device uses two parabolic trough collectors (PTCs), where each one is composed by a parabolic-shaped reflector in whose focal line is located the absorber. In this work, only half of it (one PTC) is analyzed, assuming that the other half would behave in the same way.

Thermal analysis of this kind of solar collectors has been made by some researchers [13] [14]. Kalagirou [15] performs an analysis considering all mechanisms of heat transfer for a solar tracking parabolic trough collector, Jin et al. [16] uses the Monte Carlo Ray-Trace method (MCRT) to determine the solar flux, and Hachica et al. [17] develops a numerical model contemplating the nonuniformity of the received solar radiation and the heat losses along the crosssection of the absorber tube. Huang et al. [18] coupled a thermal model with an optical model in order to predict the performance of a PTC. Other researchers have developed computational models combining the Finite Volume Method (FVM) and the MCRT method, [19] [20].

The absorber of the parabolic trough collector analyzed in this work, unlike the ones mentioned above, is not bounded by a cylindrical concentric crystal; but by a thermally isolated trapezoidal enclosure as shown in Figure 2, in order to simplify the prototype fabrication.

In this work we determine the energy flow towards the absorber throughout the day, by performing an analysis of the transfers of energy taking place between the elements of the collector, considering all the heat transfer mechanisms. The model includes an algorithm to obtain the solar irradiation as a function of time, which also depends on the geographic location of the prototype and the

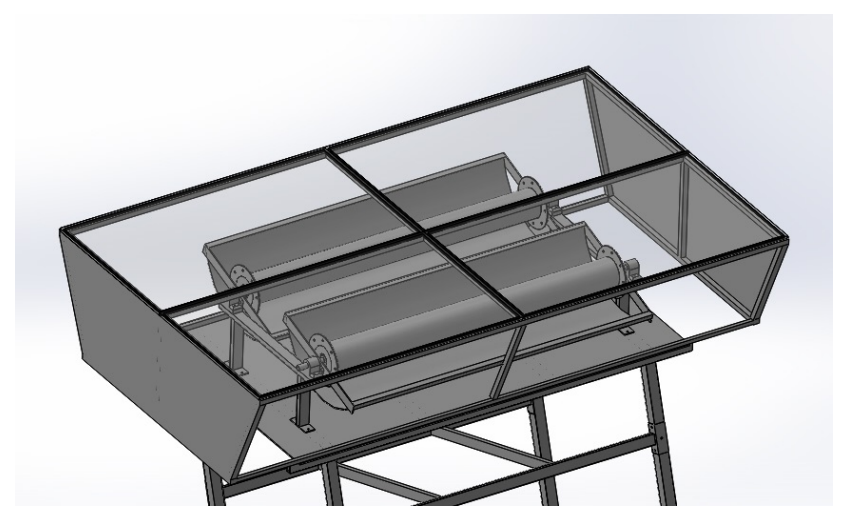

Figure 2. Solar collecting system. 
day of the year. The model is coupled with the mathematical model of the absorber of a solar adsorption refrigerator developed by Echarri et al. [12] as a boundary condition in order to iteratively obtain the desorption heat intake, as well as the evolution of the temperature in the surface of the absorber and the rest of the collector's components. This model is satisfactorily validated with experimental data.

\section{Physical Model}

The numerical model is based on an energy balance. In this balance the solar irradiation, the optical losses, as well as the thermal losses, are analyzed in order to obtain the net heat gained by the absorber. This net heat would be the responsible for temperature change on the surface of the absorber, and also for the desorption, which is a temperature-dependent process.

\subsection{Received Solar Irradiation}

In order to determine the incident solar irradiation $\left(\dot{q}_{i n c}\right)$, the Hottel's model is used [21]. With this model, the solar irradiance as a function of time can be obtained $\left(\dot{q}_{\text {sol }}\right)$, depending on the day of the year, the type of weather, the geographic location and the height above sea level.

Once the irradiance is known, it is possible to estimate the solar radiation received by the upper and lower half of the absorber.

The upper half receives the solar irradiance (both direct and diffuse components), obtaining the expression (1) for the absorbed energy per unit length.

$$
\dot{q}_{\text {inc-upper }}=2 r \dot{q}_{\text {sol }}
$$

The lower half receives the direct radiation $\left(\dot{q}_{d i r}\right)$ which is redirected by the concentrator. This magnitude depends on the captation area of the concentrator $\left(A_{c}\right)$, as well as on the reflectivity $(R)$ of the material the concentrator is built, obtaining the expression (2).

$$
\dot{q}_{\text {inc-lower }}=A_{c} R \dot{q}_{\text {dir }}
$$

The final expression for the incident radiation is as seen on equation (3). The incident radiation is further conditioned by the transmissivity of the glass cover and the absorptivity of the absorber's material. The product of these parameters $\left(L_{\text {opt }}\right)$ is a factor representing the optical losses [22].

$$
\dot{q}_{\text {inc }}=\left(\dot{q}_{\text {inc-upper }}+\dot{q}_{\text {inc-lower }}\right) L_{\text {opt }}
$$

\subsection{Heat Transfers}

During the day, the solar irradiation is concentrated and directed towards the absorber, causing a temperature increment in its surface. Then, since the absorber is not in thermal equilibrium with the rest of the collector, it transfers energy by convection to the air trapped in the enclosure, which subsequently starts transferring energy to the walls of the enclosure. 
Given the amount of energy gained for the walls of the enclosure by convection with the air, and also for the radiative transfer involving the other elements of the PTC, the walls raise their temperature. To the increase of the temperature of the walls, follows an energy transfer (radiative and convective) between the walls and the environment.

As seen on Figure 3, the energy balance for the absorber tube would include the incident solar radiation (which is the absorber's dominating energy transfer during the desorption process), the convection, and the net radiative transfer with the walls of the PTC. The net heat absorbed is given by:

$$
\dot{q}_{\text {net }}=\dot{q}_{\text {inc }}-\dot{q}_{\text {conv-abs }}-\dot{q}_{\text {rad }-a b s}
$$

In a similar way, the energy balance for each wall of the enclosure can be obtained as follows:

$$
\dot{q}_{s}=\dot{q}_{\text {conv-wi }}+\dot{q}_{\text {rad-wi }}-\dot{q}_{\text {conv-we }}-\dot{q}_{\text {rad-we }}
$$

\subsubsection{Convection Heat Transfer between the Absorber and the Surrounding Air}

Assuming that the temperature around the circumference of the absorber is uniform, the convection heat transfer between the absorber and the air trapped inside the enclosure is determined by using Newton's cooling law;

$$
\dot{q}_{\text {conv-abs }}=h A\left(T_{a b s}-T_{\text {air }}\right)
$$

where, $T_{a b s}$ is the temperature of the absorber, $T_{a i r}$ is the temperature of the air at an intermediate point between the absorber and the walls, $A$ is the heat transfer area, and $h$ is the convection heat transfer coefficient. Since the

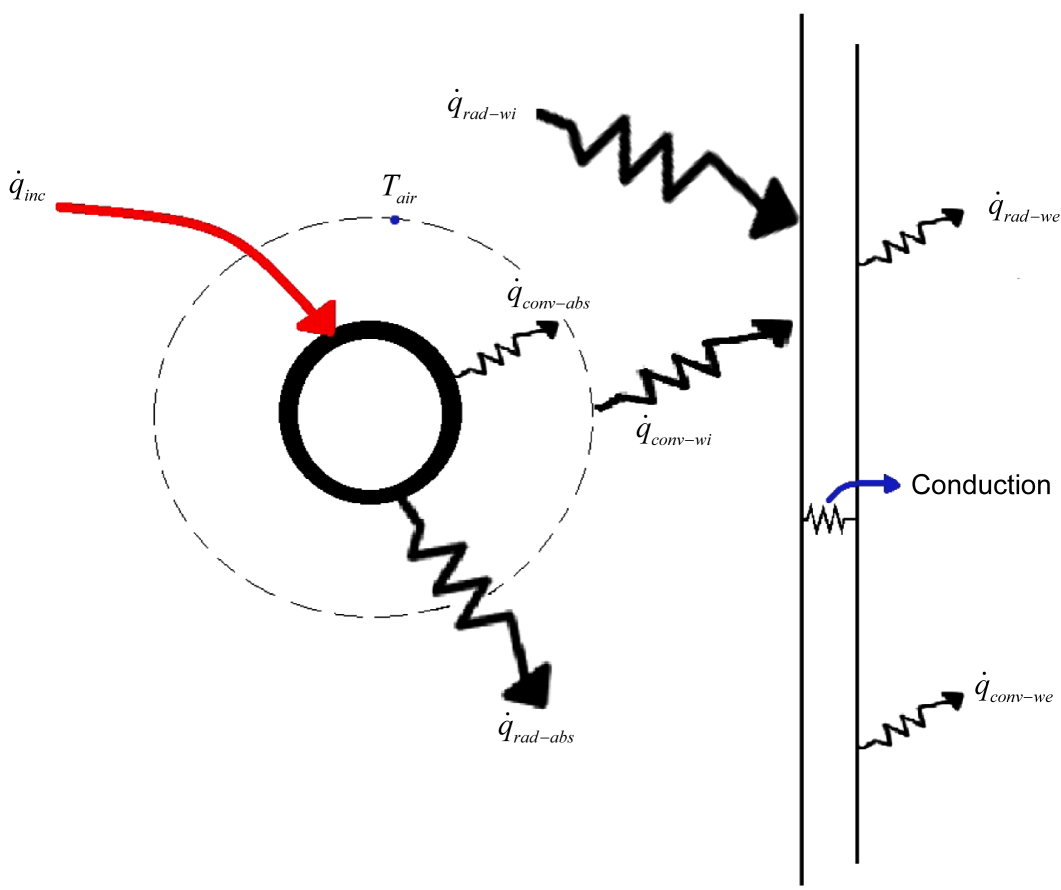

Figure 3. Energy transfers between the absorber and one of the surfaces of the thermally insulating enclosure (not to scale). 
cross-sectional area of the absorber cylinder is negligible compared to its transverse area, only the last one is considered for the heat exchanges calculations.

The convection heat transfer coefficient is evaluated through the dimensional analysis and similitude method. In this method, the conservation equations are expressed as a function of non-dimensional parameters and can be solved analytically or empirically. Once solved, the results can be applied to surfaces geometrically similar.

In this work, the convection heat transfer coefficient is determined as a function of the Nusselt number $(\mathrm{Nu})$;

$$
h=\frac{k N u}{L}
$$

where, $k$ is the thermal conductivity and $L$ is the characteristic longitude of the given element.

For natural convection on horizontal cylinders, the correlation used to determine the Nusselt number, is the one proposed by Churchill and Chu [23], where $R a$ is the Rayleigh number and Pris the Prandtl number:

$$
N u=\left\{0.6+0.378\left[\frac{R a}{\left(1+(0.559 / P r)^{9 / 16}\right)^{16 / 9}}\right]^{1 / 6}\right\}^{2}
$$

The Rayleigh number used in expression (8) is given by expression (9) [24], where $g$ is the gravity, $\beta$ is the volumetric expansion coefficient, $D$ is the diameter of the absorber and $v$ is the kinematic viscosity of the air.

$$
R a=\frac{g \beta\left(T_{a b s}-T_{a i r}\right) D^{3}}{v^{2}} \operatorname{Pr}
$$

\subsubsection{Convection Heat Transfer between the Enclosure's Walls and Its Surroundings}

The convection of the internal faces and the enclosed air is as shown on Equation (10), while the convection of the external faces and the environment (convection is assumed natural) is shown on Equation (11).

$$
\begin{gathered}
\dot{q}_{\text {conv-wi }}=h_{i} A\left(T_{\text {air }}-T_{w-i n}\right) \\
\dot{q}_{\text {conv-we }}=h_{e} A\left(T_{w-e x}-T_{a}\right)
\end{gathered}
$$

where $T_{w-i n}$ is the temperature of the internal surface of the collector wall/glass cover, $T_{w-e x}$ is temperature of the external surface of the collector wall/glass cover, $T_{a}$ is the environmental temperature, and $h_{i}$ and $h_{e}$ are the convection heat transfer coefficients in each respective case.

In order to calculate the convection heat transfer coefficient between each of the cover surfaces with the surrounding air, the dimensional analysis method is used. This way, $h_{i}$ and $h_{e}$ are determined similarly as in Equation (7).

For the cases of convective heat transfer involving the lateral and inferior faces of the enclosure, the empirical correlation found for the Nusselt number is a fol- 
lows [25]:

$$
N u=\left\{0.825+0.387\left[\frac{R a}{\left(1+(0.492 / \operatorname{Pr})^{9 / 16}\right)^{16 / 9}}\right]^{1 / 6}\right\}^{2}
$$

The Rayleigh number in Equation (12) is calculated as in Equation (13) for the cases where $h_{i}$ is being evaluated, and as in Equation (14) when $h_{e}$ is being determined.

$$
\begin{gathered}
R a=\frac{g \beta\left(T_{\text {air }}-T_{w-i n}\right) L^{3}}{v^{2}} P r \\
R a=\frac{g \beta\left(T_{w-e x}-T_{a}\right) L^{3}}{v^{2}} \operatorname{Pr}
\end{gathered}
$$

For the convective heat transfer involving the glass cover, where the internal face is assumed to be colder than the enclosed air and the external face is assumed to be at higher temperature than the environment, the expression for the Nusselt number is given by [26]:

$$
\mathrm{Nu}=0.23(\mathrm{GraPr})^{1 / 4}
$$

where the Grashof number ( Gra) is obtained as follows:

$$
G r a=\frac{g \beta(\Delta T) L^{3}}{v^{2}}
$$

The used value for $P r$ in expressions (8), (9) and (12)-(15) was obtained as the mean value of the Prandtl number for the maximum and minimum expected temperature of the enclosed air (when internal convection was analyzed) and as the as the mean value of Prandtl number for $T_{w-e x}$ and $T_{a}$ (when external convection was examined).

\subsubsection{Radiative Transfer}

The radiation emitted by the different elements of the PTC is calculated through:

$$
\dot{q}_{\text {rad }-e m}=\varepsilon \sigma T^{4} \mathrm{~A}
$$

where $\varepsilon$ is the emissivity of the material, $\sigma$ is the Stefan-Boltzmann constant, $T$ is the absolute temperature and $A$ is the radiating area.

When analyzing the radiation received by the absorber and the inward faces of the enclosure, the expression (18) is used:

$$
\dot{q}_{\text {rad-rec }}=\sum_{j} \varepsilon_{i j} F_{i j} \sigma T_{j}^{4} A_{j}
$$

where $i$ denotes the absorbing surface, $j$ the radiating surface and $\varepsilon_{i j}$ refers to the effective emissivity for two surfaces with different emissivity.

The $F_{i j}$ in expression (18) stands for the view factor between the $i^{\text {th }}$ and $f^{\text {th }}$ surfaces. These factors are determined by the Crossed Strings Method [27], excepting for the known case of a cylinder facing a plane [28].

The net heat lost by the absorber per unit length can be obtained as following: 


$$
\dot{q}_{\text {rad-abs }}=\varepsilon_{a b s} \sigma T_{a b s}^{4} A_{a b s}-\sum_{j=1}^{3} \varepsilon_{j-a b s} F_{j-a b s} \sigma T_{j}^{4} A_{j}
$$

Similarly, the net heat gained by the $i^{\text {th }}$ wall of the enclosure can be calculated as (being the absorber the 4 th surface):

$$
\dot{q}_{\text {rad-wi }}=\sum_{j=1}^{4} \varepsilon_{i j} F_{i j} \sigma T_{j}^{4} A_{j}-\varepsilon_{i} \sigma T_{i}^{4} A_{i}
$$

The outward surfaces of the collector interact with the environment, so the net radiative flow rate is given by:

$$
\dot{q}_{\text {rad-we }}=\varepsilon \sigma\left(T^{4}-T_{a}^{4}\right) A
$$

\subsubsection{Conduction}

Since the convective and radiative heat flows have been determined, the sensible heat is obtained. This heat causes a variation in the temperature of the enclosure. The new temperatures of the walls and glass cover of the collector, are calculated from:

$$
\dot{q}_{s}=m c \frac{\Delta T_{w}}{\Delta t}
$$

where $m$ is the mass of the wall and $c$ represents the specific heat of the material.

After obtaining this new central temperature, and assuming a linear temperature profile (as seen on Figure 4), Fourier's law is used in order to determine the new temperatures in the internal and external faces of the glass cover and the other walls of the enclosure, as seen from expressions (23) and (24).

$$
\begin{gathered}
\dot{q}_{\text {in }}=\dot{q}_{\text {conv-wi }}+\dot{q}_{\text {rad }-w i}=-k A \frac{T_{w}-T_{w-i n}}{e / 2} \\
\dot{q}_{\text {out }}=\dot{q}_{\text {conv-we }}+\dot{q}_{\text {rad-we }}=-k A \frac{T_{w-e x}-T_{w}}{e / 2}
\end{gathered}
$$

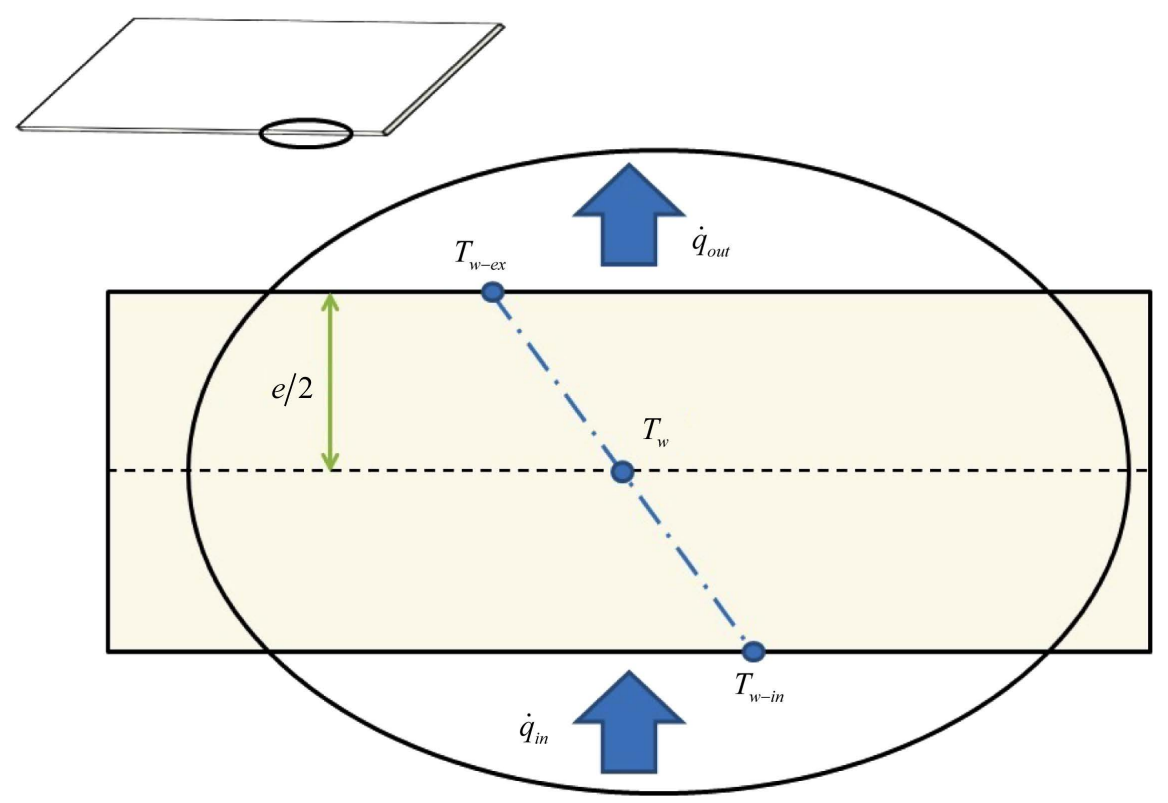

Figure 4. Application of Fourier's law. 
The temperature of the enclosed air also varies. Assuming that the convective heat being transferred from the absorber to the air is divided towards the inner faces of the enclosure's walls according to the thermal resistance of each one, the new temperature of the enclosed air can be obtained from Equation (25).

$$
T_{\text {air }}=\frac{\sum h_{j} A_{j} T_{j-i n}}{\sum h_{j} A_{j}}
$$

\subsection{Algorithm}

The algorithm is based on the physical model obtained from the heat transfer equations described above. In Figure 5 can be observed the diagram of the algorithm, which was developed in $\mathrm{c}++$ language.

In the "parameters and initial values" section is where the environmental temperature is specified and the temperatures of the PTC parts are initialized. In this section are also introduced the parameters for the particular prototype/case being evaluated: the dimensions of the elements of the PTC, view factors, properties of the materials (absorptivity of the absorber tube, reflectivity of the concentrator, transmissivity of the glass cover, thermal conductivity of the PTC elements, captation area of the concentrator, emissivity and specific heat of the PTC elements, Pr and kinematic viscosity of the air) as well as the day of the year of the desired analysis, the coordinates where the given prototype is located and

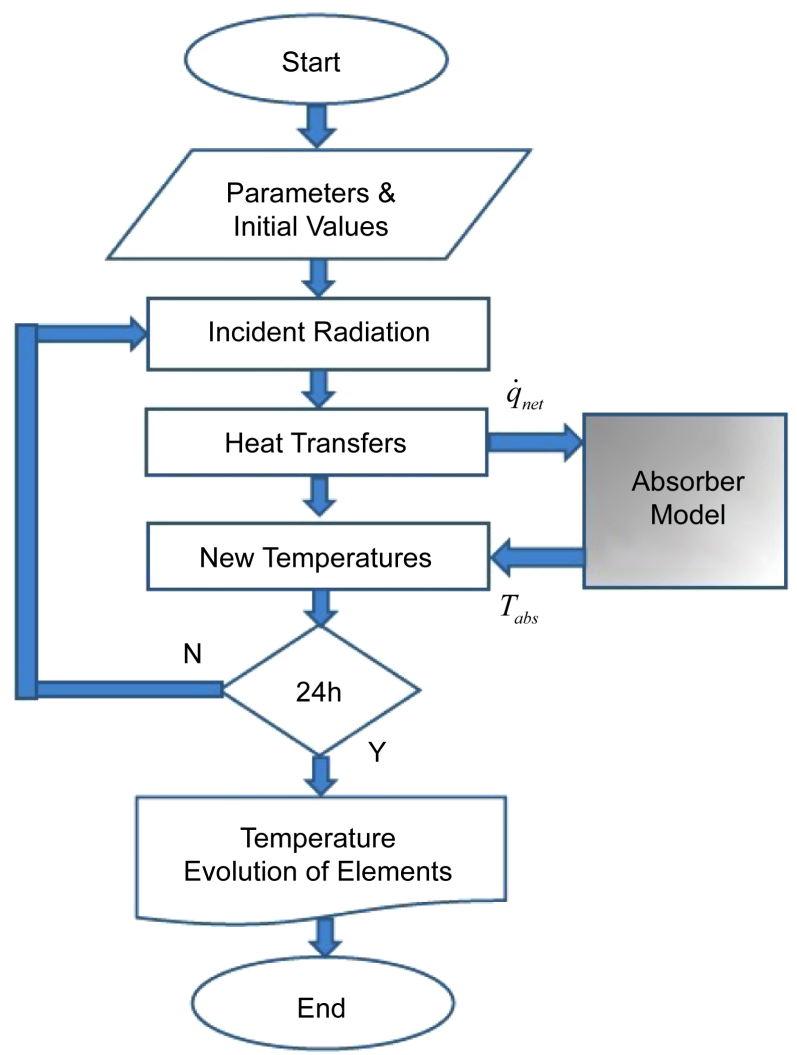

Figure 5. Simplified diagram of the computational algorithm. 
its height above sea level.

In section "incident radiation", the total solar radiation directed towards the absorber is determined, after the incoming irradiation is calculated according to the geographic location and the day of the year.

In the "heat transfers" section, the energy fluxes between each pair of elements is analyzed by determining the convection heat transfer coefficients and the net radiative transfer. The sensible heat is calculated, as well as the new temperatures of the walls of the enclosure for the next temporal step.

Since all the heat fluxes are known, the absorbed heat is calculated and given as a boundary condition to the absorber model developed by Echarri et al. [12], which determines how much of that heat is consumed by the desorption process and how much is responsible for the temperature raise in the surface of the absorber. These two models (collector and absorber) are coupled and from the "absorber model" block and the new absorber's temperature is obtained.

This process continues along the whole day, making possible to determine the temperature evolution of each one of the elements composing the PTC.

\section{Model Validation and Discussion}

As previously stated, in order to validate the thermal model, it is coupled to the numerical model of an absorber of a solar adsorption refrigerator [12]. The validation of the model is carried out by comparing the temperature of the absorber's surface of two different prototypes of SARs.

The measurements were carried out with thermocouples (type J) with a working range of $\left(-290^{\circ} \mathrm{C}\right.$ to $\left.1,190^{\circ} \mathrm{C}\right)$ with an error of $+/-1^{\circ} \mathrm{C}$. The measurements were automatically recorded with the EL-USB-TC Thermocouple Data Logger, manufactured by Lascarc Ekectrinic Inc.

In Figure 6 and Figure 7 can be observed the temperature evolution of two prototypes at different locations and different dates. In both cases, simulation results show good agreement with the experimental results.

Since the solar irradiance model employed [21] assumes a clear sky, the simulation may present differences with the results for cases in which the sky is cloudy. In Figure 6 the discrepancies between the experimental curves and the simulation is less than $4 \%$ before the presence of clouds in the scenario, after which the discrepancies increment up to $34 \%$. In Figure 7 the maximum temperature differences due to the cloudiness, found between the simulation and experimental measurements in absorbers $\# 1$ and $\# 2$, are $25 \%$ and $19 \%$ respectively.

Also, if the PTC is not completely horizontal, the temperature on both absorbers can present a slight difference between them, since the asymmetry is not contemplated in the model and air stratification may occur. In Figure 6 and Figure 7 the temperature difference between the absorbers varies up to $11 \%$ and $5 \%$ respectively. 


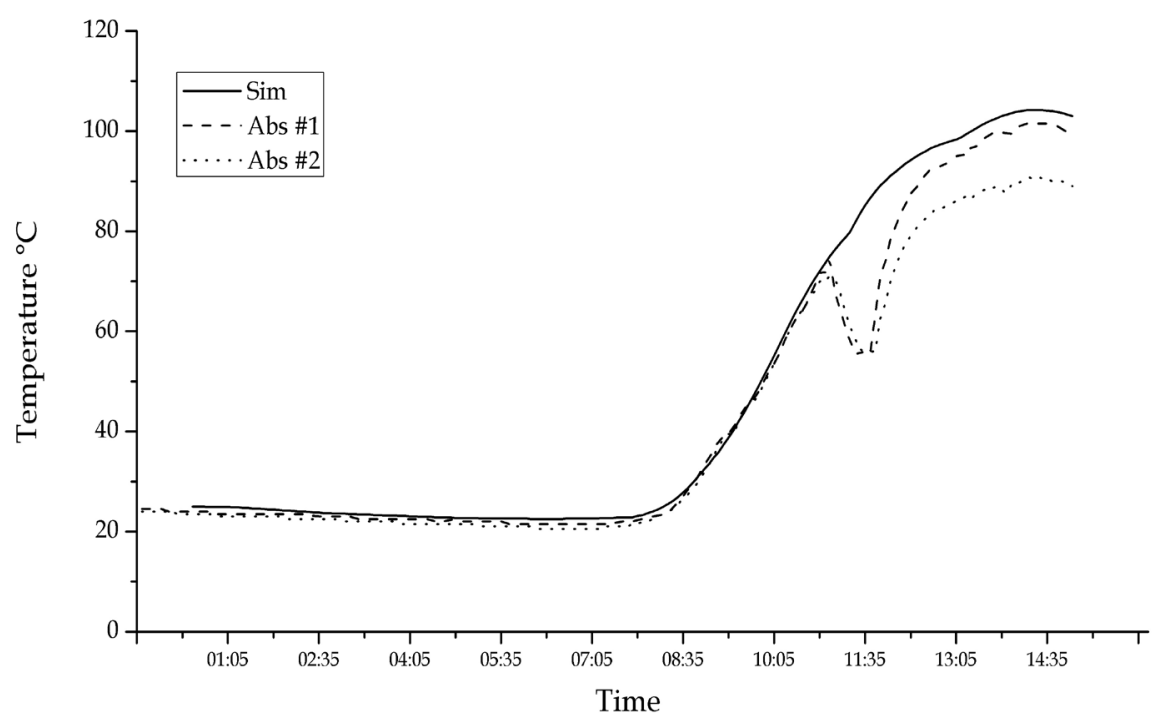

Figure 6. Temperature evolution in the surface of the absorbers of solar adsorption refrigerator located in Dominican Republic. Solid line: present model, dashed lines: experimental data.

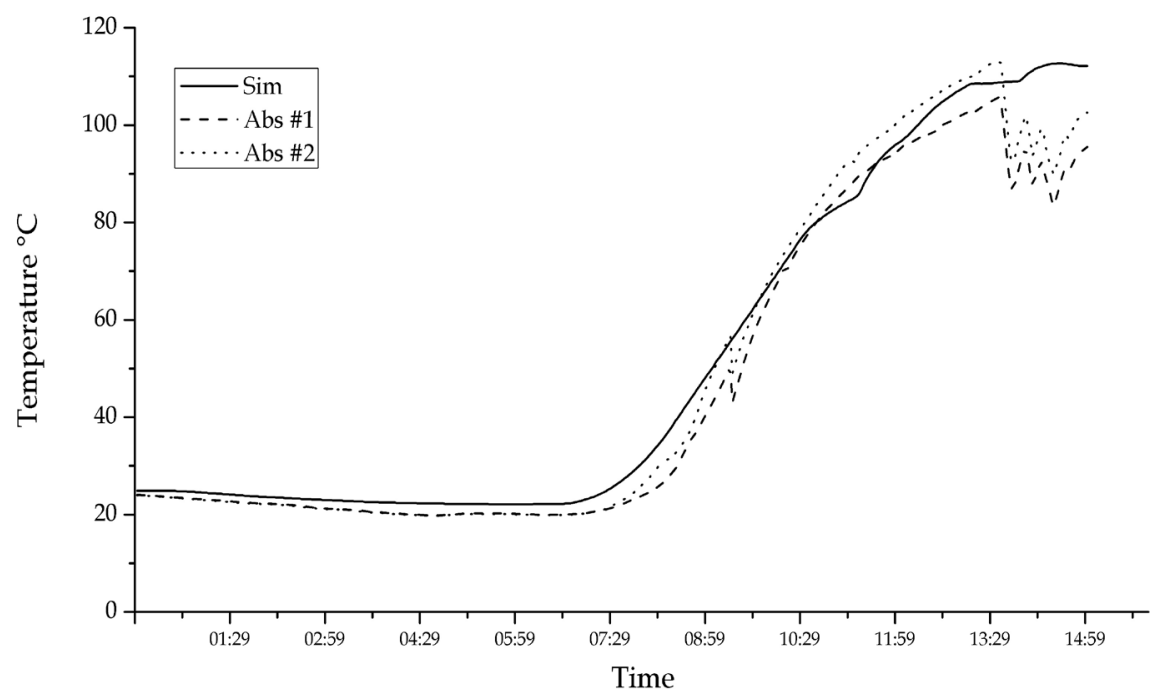

Figure 7. Temperature evolution in the surface of the absorbers of solar adsorption refrigerator located in Argentina. Solid line: present model, dashed lines: experimental data.

In Figure 8 is shown a simulation of the absorber's temperature of a solar adsorption refrigerator that uses methanol and activated carbon as refrigerant pair. It can be seen that, under the same climatic conditions, the temperature reached will differ according to the adsorption capacity of the given activated carbon (in decreasing order; CNR 115, Aquasorb and Char). This can be explained by the fact that, the greater the adsorption capacity is, the greater would be the percentage of the heat intake consumed by the desorption process; as a consequence, there would be less sensible heat available and finally, a lower temperature would be reached by the absorber's surface. 
In Figure 9 is shown a simulation of the temperature of the absorber's surface of a SAR using the same refrigerant pair, at different places (Santo Domingo: 69.96, 18.5 and Buenos Aires: 58, -34.5) during their respective summer solstice and supposing a constant $25^{\circ} \mathrm{C}$ environmental temperature. From this can be seen how the mere fact of the location of a SAR prototype can affect its behavior.

\section{Conclusions}

A detailed numerical model based on energy balance of a PTC has been developed. The proposed model included a detailed convective heat transfer analysis in which different empirical correlations have been selected according to the conditions under study and a thermal radiative heat transfer analysis based on the crossed-string method.

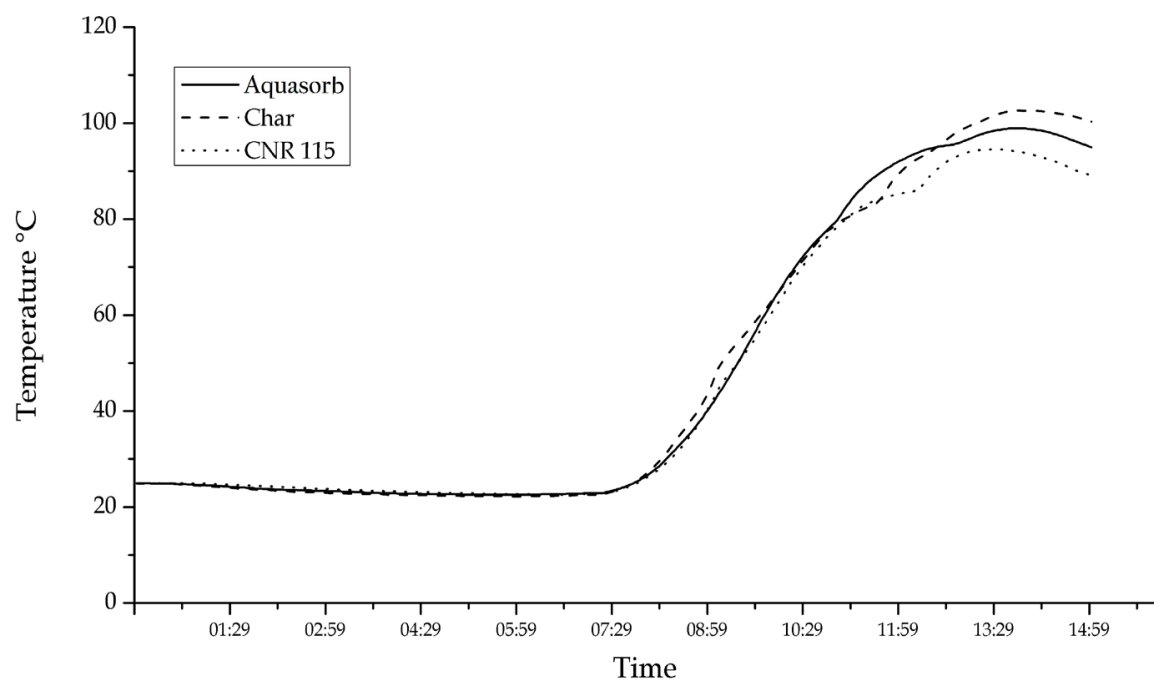

Figure 8. Temperature evolution in the surface of absorber of a SAR using different types of activated carbon.

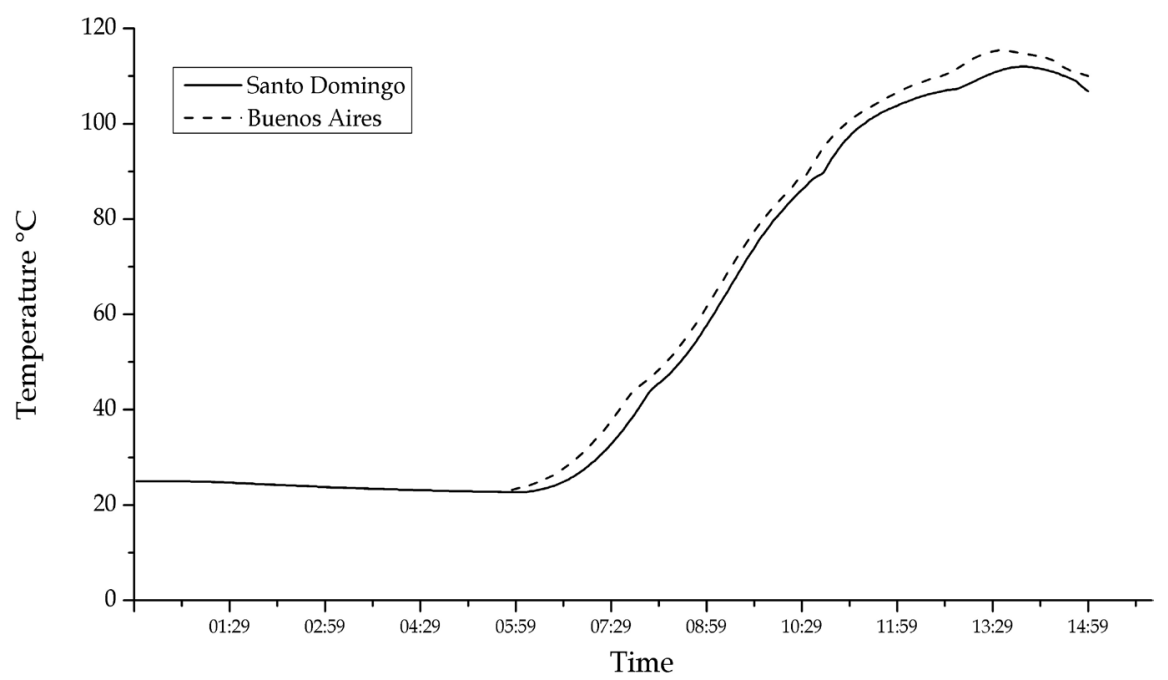

Figure 9. Temperature evolution in the surface of absorber of a SAR using methanol and CNR 115 activated carbon in different locations. 
The thermal model is validated with experimental results available after the construction of prototypes, showing a quite good agreement. Results obtained matched experimental ones, although some discrepancies are observed due to unaccounted cloudiness and air stratification effects during the prototype operation.

It is shown that the present model is capable of estimating reasonably well the heat losses and the temperature in the PTC. According to the results obtained, it can be concluded that the current numerical model is suitable for predicting the thermal behavior of the PTC under different operating conditions.

The PTC model developed in this paper can be coupled to absorbers used for different purposes; it can be paired to absorbers with a heat transfer fluid inside, and can be paired (as in this case) to a regenerator of a solar adsorption refrigerator. The model can predict accurately the net heat directed towards the absorber of a solar adsorption refrigerator based on; the structure and material properties of the system, the date and the geographic location of the prototype.

\section{Acknowledgements}

This work has been financially supported by the Ministerio de Educación Superior, Ciencia y Tecnología of Dominican Republic through projects INNOVACION 2012-2013-2E1-28 and 2015-2E4-091.

\section{References}

[1] Li, C., Wang, R.Z., Wang, L.W., Li, T.X. and Chen, Y. (2013) Experimental Study on an Adsorption Icemaker Driven by Parabolic Trough Solar Collector. Renewable Energy, 57, 223-233. https://doi.org/10.1016/j.renene.2013.01.040

[2] Boubakri, A., Guilleminot, J. and Meunier, F. (2000) Adsorptive Solar Powered Ice Maker: Experiments and Model. Solar Energy, 69, 249-263. https://doi.org/10.1016/S0038-092X(00)00063-3

[3] Anyanwu, E. (2003) Review of Solid Adsorption Solar Refrigerator i: An Overview of the Refrigeration Cycle. Energy Conversion and Management, 44, 301-312. https://doi.org/10.1016/S0196-8904(02)00038-9

[4] Leite, A.P.F., Grilo, M.B., Andrade, R.R.D., Belo, F.A. and Meunier, F. (2005) Experimental Evaluation of a Multi-Tubular Adsorber Operating with Activated Carbon-Methanol. Adsorption, 11, 543-548. https://doi.org/10.1007/s10450-005-5982-8

[5] Leite, A.P.F., Grilo, M.B., Andrade, R.R.D., Belo, F.A. and Meunier, F. (2007) Experimental Thermodynamic Cycles and Performance Analysis of a Solar Powered Adsorptive Icemaker in Hot Humid Climate. Renewable Energy, 32, 697-712. https://doi.org/10.1016/j.renene.2006.03.002

[6] Vera, S., Echarri, R., Sartarelli, A., Cyrulies, E. and Samson, I. (2008) Construcción de una heladera solar por adsorción. [Construction of a Solar Adsorption IceMaker.] Avances en Energías Renovables y Medio Ambiente, 12, 1-5.

[7] Anyanwu, E. and Ogueke, N. (2005) Thermodynamic Design Procedure for Solid Adsorption Solar Refrigerator. Renewable Energy, 30, 81-96. https://doi.org/10.1016/j.renene.2004.05.005

[8] Samson, I. and Echarri, R. (2004) Una alternativa para producción de frío con 
energía solar. [An Alternative for Cold Production Using Solar Energy.] Ciencia y Sociedad, 29, 7-25.

[9] Vera, S., Sartarelli, A., Echarri, R., Cyrulies, E. and Samson, I. (2011) Prototipos de refrigeradores solares por adsorción. [Prototypes of Solar Adsorption Refrigerators.] Avances en Energías Renovables y Medio Ambiente, 15, 41-50.

[10] Luo, L. and Tondeur, D. (2000) Transient Thermal Study of an Adsorption Refrigerating Machine. Adsorption, 6, 93-104. https://doi.org/10.1023/A:1008907518073

[11] Zhao, Y., Hu, E. and Blazewicz, A. (2012) Dynamic Modelling of an Activated Carbon-Methanol Adsorption Refrigeration Tube with Considerations of Interfacial Convection and Transient Pressure Process. Applied Energy, 95, 276-284.

[12] Echarri, R., Samsón, I., Gariaev, A. and Sartarelli, A. (2017) Dynamic Simulation of Absorber for Solar Adsorption Refrigerator: A Validated Numerical Model. Energy and Power Engineering, 9, 464-477. https://doi.org/10.4236/epe.2017.98030

[13] Padilla, R.V., Demirkaya, G., Goswami, D.Y., Stefanakos, E. and Rahman, M.M. (2011) Heat Transfer Analysis of Parabolic Trough Solar Receiver. Applied Energy, 88, 5097-5110.

[14] Wang, Y., Liu, Q., Lei, J. and Jin, H. (2014) A Three-Dimensional Simulation of a Parabolic Trough Solar Collector System using Molten Salt as Heat Transfer Fluid. Applied Thermal Engineering, 70, 462-476.

[15] Kalogirou, S.A. (2012) A Detailed Thermal Model of a Parabolic Trough Collector Receiver. Energy, 48, 298-306.

[16] Jin, J., Ling, Y. and Hao, Y. (2017) Similarity Analysis of Parabolic-Trough Solar Collectors. Applied Energy.

[17] Hachicha, A., Rodríguez, I., Capdevila, R. and Oliva, A. (2013) Heat Transfer Analysis and Numerical Simulation of a Parabolic Trough Solar Collector. Applied Energy, 111, 581-592.

[18] Huang, W., Xu, Q. and Hu, P. (2016) Coupling 2d Thermal and 3d Optical Model for Performance Prediction of a Parabolic Trough Solar Collector. Solar Energy, 139, 365-380.

[19] Cheng, Z., He, Y., Cui, F., Xu, R. and Tao, Y. (2012) Numerical Simulation of a Parabolic Trough Solar Collector with Nonuniform Solar Flux Conditions by Coupling Fvm and Mcrt Method. Solar Energy, 86, 1770-1784.

[20] He, Y.L., Xiao, J., Cheng, Z.D. and Tao, Y.B. (2011) A mcrt and fvm Coupled Simulation Method for Energy Conversion Process in Parabolic Trough Solar Collector. Renewable Energy, 36, 976-985.

[21] Hottel, H.C. (1976) A Simple Model for Estimating the Transmittance of Direct Solar Radiation through Clear Atmospheres. Solar Energy, 18, 129-134.

[22] Paredes, C.V. (2012) Diseño de captador solar cilíndrico parabólico para aplicaciones rurales en Paraguay. [Design of Cylindrical-Parabolic Solar Collector for Rural Applications in Paraguay.] Tesis, Polytechnic University of Madrid.

[23] Churchill, S.W. and Chu, H.H. (1975) Correlating Equations for Laminar and Turbulent Free Convection from a Horizontal Cylinder. International Journal of Heat and Mass Transfer, 18, 1049-1053.

[24] Kreith, F. and Bohn, M.S. (2001) Principles of Heat Transfer. 6th Edition, Cengage Learning.

[25] Cengel, Y.A. (2007) Heat and Mass Transfer (a Practical Approach). 3rd Edition, McGraw-Hill. 
[26] Vliet, G.C. (1969) Natural Convection Local Heat Transfer on Constant-Heat-Flux Inclined Surfaces. Journal of Heat Transfer, 91, 511-516. https://doi.org/10.1115/1.3580235

[27] Modest, M.F. (2013) Radiative Heat Transfer. 3rd Edition, Academic Press.

[28] Incropera, F.P. and De Witt, D.P. (1966) Fundamentals of Heat and Mass Transfer. 4th Edition, John Wiley \& Sons.

\section{Nomenclature}

\begin{tabular}{|c|c|c|c|}
\hline Sym & Comment & Sym & Comment \\
\hline$A$ & Heat transfer area & $\dot{q}_{\text {inc-upper }}$ & Solar radiation on absorber's upper half \\
\hline$A_{c}$ & Concentrator's captation area & $\dot{q}_{\text {net }}$ & Net heat absorbed by the absorber \\
\hline$c$ & Specific heat & $\dot{q}_{\text {rad-abs }}$ & Absorber's radiative heat loss \\
\hline$D$ & Diameter of absorber tube & $\dot{q}_{\text {rad-em }}$ & Emitted radiation \\
\hline$e$ & Enclosure's wall thickness & $\dot{q}_{\text {rad-rec }}$ & Received radiation \\
\hline$F_{i j}$ & View factor between surfaces “ $\hat{i}$ ' and “ & $\dot{q}_{\text {rad-we }}$ & Radiative heat transfer to outer face of enclosure's wall \\
\hline$g$ & Gravity & $\dot{q}_{r a d-w i}$ & Radiative heat transfer to inner face of enclosure's wall \\
\hline$h$ & Convective heat transfer coefficient & $\dot{q}_{s}$ & Sensible heat of enclosure's walls \\
\hline$h_{e}$ & $\begin{array}{l}\text { Outer-face convective heat transfer coefficient } \\
\text { of enclosure's wall }\end{array}$ & $\dot{q}_{\text {sol }}$ & Solar irradiance \\
\hline$h_{i}$ & $\begin{array}{l}\text { Inner-face convective heat transfer coefficient } \\
\text { of enclosure's wall }\end{array}$ & $r$ & Radius of absorber tube \\
\hline$k$ & Thermal conductivity & $R$ & Concentrator's reflectivity \\
\hline$L$ & Characteristic longitude & $R a$ & Rayleigh number \\
\hline$L_{o p t}$ & Collector's optical losses & $T_{a}$ & Environmental temperature \\
\hline$m$ & Mass & $T_{a b s}$ & Absorber's surface temperature \\
\hline$N u$ & Nusselt number & $T_{w}$ & Central temperature of enclosure's wall \\
\hline $\operatorname{Pr}$ & Prandtl number & $T_{w-e x}$ & Outer-face temperature of enclosure's wall \\
\hline PTC & Parabolic trough collector & $T_{w-i n}$ & Inner-face temperature of enclosure's wall \\
\hline$\dot{q}_{\text {conv-abs }}$ & Absorber's convective heat loss & $\beta$ & Volumetric expansion coefficient \\
\hline$\dot{q}_{\text {conv-we }}$ & Convective heat transfer to outer face of enclosure's wall & $\varepsilon$ & Emissivity \\
\hline$\dot{q}_{\text {conv-wi }}$ & Convective heat transfer to inner face of enclosure's wall & $\varepsilon_{i j}$ & Effective emissivity between surfaces “ $i$ " and “ $"$ \\
\hline$\dot{q}_{\text {dir }}$ & Direct solar radiation & $v$ & Kinematic viscosity \\
\hline$\dot{q}_{\text {inc }}$ & Incident solar irradiation & $\sigma$ & Stefan-Boltzmann constant \\
\hline$\dot{q}_{\text {inc-lower }}$ & Solar radiation on absorber's lower half & & \\
\hline
\end{tabular}

